\title{
UMA LEITURA DO SUJEITO VIRTUAL NAS MÍDIAS SOCIAIS E AS CONTRIBUIÇÕES DA ANÁLISE DO DISCURSO
}

PLÁBIO MARCOS MARTINS DESIDÉRIO 


\section{UMA LEITURA DO SUJEITO VIRTUAL NAS MÍDIAS SOCIAIS E AS CONTRIBUIÇÕES DA ANÁLISE DO DISCURSO}

Resumo: O objetivo do trabalho é analisar do sujeito virtual nas mídias sociais, a partir, da perspectiva da Análise do Discurso. Os sujeitos podem ser percebidos como sujeitos virtuais, pois estão condicionados por características do discurso virtual. Para essa compreensão utilizamos a perspectiva da AD, pois possibilita analisar como o sujeito é atravessado pelo discurso. Utilizaremos autores como M. Peuchêx, M. Foucault, C. Haroche e E. Orlandi

Palavras-chave: sujeito virtual; mídias sociais; Análise do Discurso.

LECTURA DE LA ASIGNATURA EN MEDIOS SOCIALES VIRTUALES Y LOS APORTES DE ANÁLISIS DEL DISCURSO

Resumen: El objetivo es analizar el tema virtual en los medios sociales, desde la perspectiva del análisis del discurso. Los temas pueden ser percibidos como sujetos virtuales, ya que están condicionados por las características del discurso virtual. Para utilizar esta comprensión de la perspectiva de la EA, ya que permite analizar cómo el sujeto es atravesado por el discurso. Usaremos autores como M. Peuchêx, M. Foucault, C. Haroche y E. Orlandi.

Palabras clave: según virtuales; redes sociales; Análisis del Discurso.

READING THE SUBJECT IN VIRTUAL SOCIAL MEDIA AND THE CONTRIBUTIONS OF DISCOURSE ANALYSIS

Abstract: The objective is to analyze the virtual subject in social media, from the perspective of discourse analysis. The subjects may be perceived as virtual subjects because they are conditioned by characteristics of virtual discourse. To use this understanding the perspective of $A D$, since it allows to analyze how the subject is crossed by the discourse. We will use authors as M. Peuchêx, $M$. Foucault, C. Haroche and E. Orlandi.

Keywords: subject virtual; social media; Discourse Analysis. 


\section{INTRODUÇÃO}

Nos últimos anos as transformações tecnológicas possibilitaram que novos espaços e novas formas de interlocução surgissem e se aprimorassem. A internet possibilitou novas formas de interação, mas não conseguiu substituir as formas tradicionais de interação. Para Sodré (2011) a internet, e em especial as mídias sociais não estão estabelecendo uma nova forma de construção de discussão e conscientização política, isto é, não estão produzindo uma emancipação social, superando instituições tradicionais, como por exemplo, a universidade. Porém, as mídias sociais estabelecem contatos diferentes dos que existiam antes da existência da internet. Elas possibilitam que os sujeitos agora enunciam comentários a respeito de uma infinidade assuntos e questões.

As mídias sociais são consideradas na atualidade, como uma nova "fronteira" para o processo comunicativo. Essa afirmação entre outras se baseia, por exemplo, numa concepção naturalizadas dos processos tecnológicos. A expansão da internet provocou possivelmente um discurso de que as novas experiências virtuais possam ser explicadas por elas mesmas, estimulando uma preguiça epistemológica. Para analisar de forma mais elaborada é necessário abandonar um perspectiva técnica, e procurar compreender os processos de discursividades presentes nesses espaços virtuais.

Este trabalho, portanto, procura se afastar de uma visão meramente técnica para analisar como o espaço das mídias sociais é ocupado por indivíduos que se assujeitam ao discurso do virtual e, por isso podem ser percebidos como sujeitos virtuais. Ao participarem do ciberespaço, esses indivíduos são condicionados pelas características desse discurso como analisaremos mais adiante. Para essa análise utilizaremos a Análise do Discurso (AD) de linha francesa e outros autores que contribuem para compreender as características do discurso da virtualidade na contemporaneidade.

\section{ANÁlise do DISCURSO E A QUESTÃo DO SUJEITO}

Para analisar o comportamento dos indivíduos nas mídias sociais é necessário perceber a posição dos mesmos nesses espaços, bem como a construção desses indivíduos em sujeitos do discurso. A Análise de Discurso é a nossa ferramenta teórica metodológica, e por isso tratar os internautas em sujeitos passa 
a ser uma estratégia de análise. Como todo sujeito é interpelado pela ideologia (Pêcheux, 2001), os indivíduos ao expressarem suas opiniões nos sites de relacionamentos, os fazem de acordo com um processo, que de acordo com a $A D$ é chamado de formações imaginárias. As formações imaginárias são alimentadas pela ideologia e como observou Pêcheux (2009, p. 82) que "[...] todo processo discursivo se inscreve numa relação ideológica de classes". Essa afirmação pêcheuxeana considera que o discurso é construído, a partir, das relações ideológicas e, por conseguinte imaginárias que surgem dos processos sociais.

Para compreender como o sujeito é percebido pela $A D$, essa entendida como disciplina e/ou método/teoria recorremos a autores que analisaram, ou pelo menos em alguns momentos de suas análises colocaram a questão do sujeito como um elemento pertinente. Como nossa filiação á AD é a francesa, recorreremos a pensadores que propuseram analisar a questão do sujeito, a partir, da AD. Os primeiros a serem destacados são considerados os fundadores da AD francesa: $M$. Pêcheux e M. Foucault.

O objetivo deste trabalho sobre a análise do sujeito virtual, não é esgotar as possibilidades de compreendê-lo. É analisar elementos que possam contribuir para a compreensão de uma possível construção subjetiva contemporânea, o sujeito virtual. É necessário compreender como esse sujeito virtual se insere numa relação discursiva, pois o indivíduo como sujeito é a todo o momento interpelado pela ideologia, como apontou M. Pêcheux.

Pêcheux (2009) ao analisar a questão do discurso e sua relação com o sujeito - proposta deste trabalho - retomou a perspectiva de L. Althusser. Este considera que os indivíduos são constituídos em sujeitos, a partir, de condições materiais, operado pela ideologia. Uma questão pertinente que Pêcheux observa é a concepção ideológica do sujeito, de que todo o indivíduo possui uma subjetividade única, universal. Uma das críticas que o autor realiza é contra o subjetivismo presente nas questões abordadas sobre o sujeito.

Ao utilizar Althusser como referência, Pêcheux (2009) analisa como a Ideologia é compreendida na verdade como formações ideológicas, pois não é um conceito idealista, mas "concreto", isto é, histórico. São essas formações ideológicas que irão constituir a forma-sujeito, como por exemplo, o jurídico.

Como afirma Pêcheux,

(...) É a ideologia que fornece as evidências pelas quais "todo mundo 
sabe" o que é um soldado, um operário, um patrão, uma fábrica, uma greve etc., evidências que fazem com que uma palavra ou enunciado "queiram dizer o que realmente dizem" e que mascaram, assim, sob a "transparência da linguagem", aquilo que chamaremos o caráter material do sentido das palavras e dos enunciados. (PÊCHEUX, 2009, p. 146).

O sujeito está intrinsecamente ligado às formações discursivas, como um processo advindo das formações ideológicas. O sujeito, portanto, é o indivíduo interpelado pelas formações ideológicas. O sujeito se "assujeita" ao processodiscurso, operacionalizado por processos ideológicos e materializados na linguagem. Por isso, como afirmou Pêcheux (2009, p. 150) “(...) Podemos agora precisar que a interpelação do indivíduo em sujeito de seu discurso se efetua pela identificação (do sujeito) com a formação discursiva que o domina (isto é, na qual ele é constituído como sujeito) (...)".

Essa perspectiva de Pêcheux (2009) traz considerações a respeito da forma-sujeito, isto é, de como o indivíduo ao se assujeitar às formações discursivas, incorporam historicamente os processo ideológicos. Quando, Pêcheux - a partir, de Althusser - observa que a ideologia interpela os indivíduos em sujeitos, os sujeitos são constituídos discursivamente, não existem sujeitos fora das formações discursivas, pois os indivíduos são seres de linguagem (FOUCAULT, 2000). Essas considerações remetem para a questão que estamos procurando problematizar, a do "sujeito virtual". Identificando formações discursivas na contemporaneidade que assujeitam os indivíduos nos discursos do universo virtual (ciberespaço) percebe-se como os indivíduos são interpelados pela ideologia da revolução tecnológica.

Essa revolução tecnológica possibilitou a ascensão extraordinária da internet e a existência de um novo processo de conexão entre pessoas. Esse processo tem como uma dos principais expoentes, os sites de relacionamento (Facebook, Orkut, Twitter) que são nomeados como mídias sociais. Essas mídias sociais (ou redes) - porém, preferimos utilizar o termo mídias sociais, pois redes é um processo mais amplo na comunicação - estão procurando estabelecer e potencializar formas de interação entre os indivíduos.

As mídias sociais são um espaço em que os sujeitos estão se assujeitando à formações discursivas que os orientam a serem identificados na forma-sujeito como sujeitos virtuais. Quais seriam essas formações discursivas que estão 
presentes nessa orientação? O sujeito virtual tornou-se possível, porque uma forma-sujeito está sendo operada discursivamente, a partir de formações discursivas que orientam os indivíduos nos espaços virtuais. Quais seriam essas formações discursivas que inserem os indivíduos na forma-sujeito virtual?

Pêcheux (2009) considera que o "sempre-já" sujeito é um pré-construído e, portanto, um elemento exterior ao discurso, isto é, um efeito ideológico. Esse efeito ideológico produz dois tipos de esquecimento. O primeiro esquecimento, como abordado, refere-se a inserção do sujeito à formação discursiva que o "domina". O segundo é a "seleção" por parte do sujeito na formação discursiva enunciados de forma parafrástica.

Foucault (2006) considera que o autor é também um processo discursivo, pois mesmo considerando a importância da existência de um indivíduo que fala, escreve, o mesmo está submetido à ordem do discurso. Foucault identifica o autor como um sujeito que "produz", ou melhor, reúne as condições para enunciar um tipo de discurso, seja científico ou literário. O autor consegue ser um sujeito que utiliza os recursos disponibilizados pelas formações discursivas, presentes nas instituições e que consegue imprimir uma identidade, um reconhecimento individual.

No entanto, o que se pode perceber nessa análise é que o sujeito é uma construção discursiva, como ocorre até mesmo com a definição de autor. Foucault observa que nos tipos de discursos como o científico e literário, o autor possui variações na sua importância. Na modernidade o discurso científico relega o autor para segundo plano, diferente do literário que reforça a posição do autor na produção das obras. Para compreender como Foucault elabora as considerações sobre a questão do autor, recorremos à sua análise, para procurar compreender como o sujeito e sua perspectiva:

Seria absurdo negar, é claro, a existência do indivíduo que escreve e inventa. Mas penso que - ao menos desde uma certa época - o indivíduo que se põe a escrever um texto no horizonte do qual paira uma obra possível retoma por sua conta a função do autor: aquilo que desenha, mesmo a título de rascunho provisório, como esboço da obra, e o que deixa, vai cair como conversas cotidianas. Todo este jogo de diferenças é prescrito pela função do autor, tal como ele, por sua vez, a modifica (...) (FOUCAULT, 2006, p. 28-29). 
Essas considerações a partir da perspectiva de Foucault remetem para a questão de como o sujeito se insere em diferentes práticas discursivas. Se para o pensador, o autor está inserido em discursos - mesmo considerando a presença do indivíduo "real" - existe uma construção institucional do sujeito. A "morte" do sujeito é a possibilidade da existência de muitas formas de sujeito, ou que formas em que os indivíduos se assujeitam à formações discursivas. Portanto, não existe o "sujeito", mas formas assujeitadas, nas quais os indivíduos incorporam discursos que representam inclusive a forma-sujeito ou sujeito-discurso.

A forma-sujeito é um termo que tem ocupado muitos pensadores em suas análises. M. Pêcheux em suas obras analisou a relação entre sujeito e discurso, ressaltando a importância de considerar que o sujeito existe na linguagem. Iremos utilizar também os subsídios fornecidos pelas analises de C. Haroche (1992). A autora ao analisar como o sujeito se condiciona o discurso, observa dois momentos históricos e seus condicionamentos discursivos para a constituição que chamaremos de forma-sujeito: religioso e o jurídico.

Para Haroche (1992) na Idade Média existiu um sujeito religioso, submetido às "práticas religiosas cristãs" determinado, portanto, pela linguagem religiosacristã. A autora se preocupa em analisar como ocorreu a mudança da forma-sujeito religiosa, para a forma-sujeito jurídica. Para isso Haroche apresenta a questão da ambiguidade (o linguístico e o extralinguístico) no discurso ou mesmo entre o enunciado e o sujeito. A proposta da autora não é descrever as ambiguidades que ocorrem na linguística, mas perceber como a mesma interfere na constituição do sujeito, primeiro o religioso e depois o jurídico. Para isso ela analisa como no discursivo ocorrem o processo linguístico e também ideológico.

Haroche (1992) considera que no discurso religioso, principalmente cristão, e depois o jurídico, há uma presença da subjetividade, porém com diferenças entre os tipos de discursos. È nessas diferenças que nos concentraremos para analisarmos como a autora faz o percurso para identificar as mudanças desses dois tipos de discursos e como poderemos analisar a constituição da formasujeito virtual. Haroche aponta que na Idade Média os indivíduos submetidos aos dogmas religiosos não conseguiram desenvolver a concepção de indivíduo autônomo. Ou melhor, não houve a possibilidade na Idade Média de se constituir um indivíduo autônomo, pois até mesmo a ideia de subjetividade estava vinculada ao dogma religioso e a própria ordem feudal. 
Entretanto, a partir do século XV, com a Reforma Protestante e com o crescimento da burguesia europeia, a autonomia do indivíduo começa a ser destacada. As mudanças religiosas provocadas pela Reforma protestante e até mesmo pelo movimento religioso-moral do jansenismo contribuíram para que a leitura bíblica, seu entendimento circulasse e com isso os indivíduos pudessem obter a consciência dos seus através do entendimento da "palavra" divina. Haroche (1992) ao exemplificar o movimento janseniano ressalta como o mesmo procurou racionalizar a língua e seu enunciado.

O que é importante destacar é como a constituição do sujeito jurídico é realizado pelo assujeitamento dos indivíduos à linguagem política-jurídica e que umas rupturas com a forma-sujeito anterior (religiosa) é “ideia” de autonomia. A percepção dos indivíduos de sua autonomia jurídica e até mesmo consciente e responsável dos seus pensamentos e atos é uma construção do processo de assujeitamentoà essa nova ordem jurídica que se estabelece. Essa perspectiva nos fornece subsídios para compreender como a forma sujeito virtual se constitui no processo histórico da chamada revolução tecnológica e/ou digital.

Outra análise pertinente é realizada por Authier-Reveuz (1998) sobre como o sujeito ao enunciar o discurso é "atravessado" por outros discursos, encontrando a presença do outro no dizer. A autora observa que o discurso é algo que possui uma heterogeneidade, que ela destaca também como as "não-coincidências do dizer". O sujeito do discurso se encontra com várias não-coincidências do dizer da enunciação. O que envolve nesse processo são posições ocupadas pelos sujeitos, jogo das não-coincidências e até mesmo os gêneros dos discursos. Porém o que iremos destacar é como na enunciação existe sempre uma heterogeneidade nos discursos. Destacamos duas imagens como apontados por Authier-Reveuz (1998), a não-coinciência interlocutiva e a nãocoincidência do discurso consigo mesmo.

A não-coincidência interlocutiva como aponta a autora é a presença do outro no sentido da psicanálise (inconsciente), no discurso do enunciador. Na interlocução existe a presença de sentido que seja compartilhado, ou mesmo as divergências na interlocução. Na outra a não-coincidência do discurso consigo mesmo, Authier-Reveuz (1998) refere essa imagem ao dialogismo bakhtiniano. Nessa imagem pode-se identificar a presença de muitos sentidos de palavras e posições do dizer num determinado enunciado. Althuer-Reveuz ao retomar a 
perspectiva de Bahktin, aponta para a questão do interdiscurso e a importância de compreender como as não-coincidências do dizer é um processo que está além de um mero jogo, pois envolve questões semânticas, como também externas ao discurso e que interfere na interdiscursividade.

Os sentidos são operados de forma heterogênea pelo enunciador. Mesmo procurando alcançar um sentido transparente no discurso, o sujeito está a todo o momento sendo condicionado por sentidos que procuram, mesmo que explicitamente o sujeito procure "fixar" o UM sentido, como aponta Authier-Reveuz (1998). A não-coincidência do dizer remete para a questão de heterogeneidade do discurso e que a autora afirma a importância de perceber que não existe uma homogeneidade discursiva. O sujeito, portanto, ao entrar na cena enunciativa está sempre condicionado às heterogeneidades do discurso, pois os sentidos são polissêmicos, mesmo que o sujeito enuncie de forma parafrástica.

Essa perspectiva "aberta" por Authier-Reveuz nos orienta a perceber como o sujeito está condicionado aos processos linguísticos e aos sentidos heterogêneos presentes no discurso. Se as palavras são porosas como afirma a autora é porque os sentidos as atravessam e por isso, o sujeito está constantemente sendo "assujeitado" nesses sentidos. O Outro como identificamos nas análises de Authier-Reveuz como sendo a exterioridade discursiva, que constitui o interdiscurso, e que, numa perspectiva psicanalítica, interpela o indivíduo em sujeito, como retomado e destacado em M. Pêcheux.

Retomando as discussões sobre um tipo de sujeito virtual que está predominando no ciberespaço, percebe-se que esses indivíduos estão se assujeitando a determinadas formações discursivas. Essas formações discursivas consideram que o ciberespaço possibilita que os indivíduos possam exercer sua liberdade e expor comentários e opiniões de acordo com as posições que os indivíduos possuem. Porém, essas posições são também estabelecidas por relações de poder, pois o discurso também é atravessado pelo poder. Essas relações de poder como um processo discursivo estabelecem as formas como os indivíduos produzem/reproduzem os discursos e no caso dos sites de relacionamento, os comentários e opiniões dos internautas sobre produtos midiáticos.

Os usuários dos sites de relacionamento e também os que acessam os portais de notícias, expressam seus comentários, a partir de perfis e cadastros, mesmo que simplificados. É nessa criação é possível identificar algumas posi- 
ções desses indivíduos como sujeitos na apropriação e construção de discursos. Esse processo de assujeitamento é compreendido como um processo em que os sujeitos são interpelados pela ideologia. E a ideologia como destacado tem o papel de produzir sentidos, entre a linguagem o mundo (ORLANDI, 2009).

É nesse sentido que os sujeitos determinados pela ideologia- não imobilizados e nem "enganados"- ao se expressarem verbalmente ou não, se inscrevem em formações discursivas estabelecidas, a partir de uma relação de sentido estabelecida entre a linguagem e a história. É essa relação de sentido que constitui o assujeitamento dos indivíduos às formações discursivas. Os indivíduos se afiliam aos sentidos quando reproduzem/produzem os discursos, porém não possuindo o controle disso.Porém os sujeitos não percebem as estratégias discursivas,acreditam que a palavra possui uma imanência na realidade, é abstrata e transparente e como Orlandi observa a AD é um procedimento analítico que desmistifica essa percepção.

(...) No entanto, se levamos em conta, como a Análise de Discurso, a ideologia, somos capazes de aprender, de forma crítica, a ilusão que está na base do estatuto da literalidade: o fato de que ele é produto histórico, efeito de discurso que sofre as determinações dos modos de assujeitamento das diferentes formas-sujeito na sua historicidade e em relação às diferentes formas de poder. $O$ falante não opera com a literalidade como algo fixo e irredutível, uma vez que não sentido único e prévio, mas um sentido instituído historicamente na relação do sujeito com a língua e que faz parte das condições de produção do discurso. (ORLANDI, 2008, p. 51-52).

Para Orlandi ao analisar uma questão do sujeito colocada por Benveniste, afirma que "(...) não é o sujeito que apropria da língua, mas, há uma forma social da apropriação da linguagem em que está refletida a ilusão do sujeito, isto é, sua interpelação feita pela ideologia" (ORLANDI, 2001, p. 45). A partir, dessa afirmação se pode perceber a determinação histórico-social sobre o sujeito, como a autora ressalta. $O$ sujeito ao ser interpelado pela ideologia, que é construída historicamente, se insere no jogo enunciativo, sendo atravessado por interdiscursos. Nesse caso os indivíduos que estão nos espaços virtuais participam desse jogo enunciativo, porém a formação discursiva que atravessa a todos, o pré-construído é o discurso que os indivíduos estão conscientes das opiniões que emite e as dominam. 
Nos espaços virtuais, os indivíduos se posicionam como "livres" em suas comunidades e perfis. A interpelação desses usuários pela ideologia se dá na articulação de muitos interdiscursos. Possivelmente o principal interdiscurso que pode ser percebido como o intradiscurso nas enunciações é a ideologia do sujeito iluminista, que "ainda" conserva sua ressonância. Nos sites de relacionamentos, os usuários numa primeira aproximação se comporta como sendo portadores de uma consciência livre e independente de fatores "externos". Essa percepção foi observada por Pêcheux e retomada por Orlandi (2001) quando trata da questão do esquecimento operado pelos sujeitos no processo de enunciação.

Orlandi (2001) ao considerar a memória como interdiscurso, abre a perspectiva para a atuação do esquecimento no processo enunciativo. Para analisar esse processo é necessário recorrer a afirmação da autora:

(...) O sujeito se constitui e se significa por ser afetado ("o indivíduo é interpelado em sujeito pela ideologia") pela língua e pelo mundo (relação do simbólico e da história "a discursividade é a inscrição doe efeitos da língua, sujeita a falta, na história”). (ORLANDI, 2001, p. 46).

$\mathrm{Na}$ articulação dos interdiscursos analisados, a partir, das considerações anteriores, percebe dois discursos, ou melhor, dois intradiscursos presentes na forma-sujeito dos usuários das mídias sociais. Eles se articulam, sendo que esses discursos se baseiam em significados construídos histórico-socialmente. Um desses discursos que atravessa os usuários é a inserção dos indivíduos na revolução tecnológica, na nova era da informação como muitos apregoam. Como afirma Castells (2001) a era da informação possibilitou que uma nova sociedade se estabelecesse: a Sociedade em Rede. Nessa "nova sociedade" o processo em rede passa a ser o novo "ethos" das relações sociais.

O discurso da "cultura virtual" passa a ser um jogo discursivo em que os indivíduos não somente leem textos, mas também se assujeitam aos mesmos. Os usuários das mídias sociais ao exporem seus comentários, os fazem, a partir, de muitas leituras, porém também incorporam leituras com diferentes significados. Nos sites de relacionamento, bem como os portais da internet que se abrem para que os usuários se manifestem, a forma-sujeito que prevalece é a do indivíduo que "domina” seu discurso, isto é, os usuários ao entrar no jogo discursivo, incorporam a memória discursiva e o esquecimento dos dizeres anteriores. 
Orlandi analisa como a ideologia realiza um trabalho de articulação entre a linguagem, os indivíduos e o mundo "real" que existe simbolicamente. Para isso os indivíduos se assujeitam na forma-sujeito discursiva. Apontaremos o que autora observa:

(...) Atravessado pela linguagem e pela história, sob o modo do imaginário, o sujeito só tem acesso a parte do que diz. Ele é materialmente dividido desde sua constituição: ele é sujeito de e é sujeito à. Ele é sujeito à língua e à história, pois para se constituir, para (se) produzir sentidos ele é afetado por elas. (...)

(...) O trabalho ideológico é um trabalho da memória e do esquecimento pois é só quando passa para o anonimato que o dizer produz seu efeito de literalidade, a impressão do sentido-lá: é justamente quando esquecemos quem disse "colonização", quando, onde e porquê, que o sentido de colonização produz efeitos (...). (ORLANDI, 2009, p. 48-49).

Essas considerações da autora remetem para a percepção de como o sujeito ao operar a linguagem, se insere numa ordem simbólica, constituída ideologicamente e construída historicamente. Nessa perspectiva podemos analisar como os sujeitos que estão no processo de recepção, sejam os usuários das mídias sociais e dos portais, ou mesmos das chamadas mídias tradicionais como a televisão. Para compreender como os indivíduos participam das novas e "velhas" plataformas ou suportes tecnológicos é necessário perceber as mudanças da forma-sujeito nos últimos anos.

\section{O SUJEITO VIRTUAL E AS MÍDIAS SOCIAIS}

As mudanças provocadas pela tecnologia nos últimos anos estão "inundando" a sociedade com novos e funcionais gadgets. Mas, não apenas os gadgets, e sim também a possibilidade da interação entre as pessoas, através de sites que potencializam essa interação. Essa potencialização condiciona/incentiva os indivíduos a saírem de um "anomimato" que existe nas mídias tradicionais e que esses usuários procuram expor suas opiniões. Contudo, é necessário destacar que essa "saída" do anonimato nas mídias sociais não é realizada de forma espontânea, em que os indivíduos se posicionam como detentores do discurso. 
As mídias sociais potencializam a participação dos indivíduos em suas plataformas digitais, porém, não se pode considerar que esses sites de relacionamentos tornaram-se outra "linguagem" que substituirá as mídias tradicionais, como cinema, televisão ou mesmo a mais tradicional de toda: o contato humano. Não é possível negar que as mídias sociais possuem uma importância considerável, tendo centenas de milhões de usuários em praticamente todos os países. Outrossim, devemos ter cuidado em analisá-las apenas através da características técnica, acreditando que o escopo das mesmas as explicam por si só.

Uma das críticas que realizamos sobre as mídias sociais é sobre o discurso que circula na contemporaneidade e defende uma possível independência dos indivíduos nesses novos suportes. Como apontamos anteriormente, esse discurso que circula funciona como um interdiscurso e que condiciona na constituição da forma-sujeito virtual. Essa forma-sujeito coloca os indivíduos na posição de sujeitos que incorporaram os significados de formações discursivas de uma nova situação histórica: a digitalização cada vez maior da realidade.

A forma-sujeito virtual que insere os indivíduos nessa linguagem procura condicioná-los à certas formações discursivas construídas historicamente, principalmente a partir, do sistema capitalista e das características modernas. O capitalismo contribuiu para que o indivíduo torna-se mero consumidor de produtos e serviços e a modernidade construindo sentidos para suas ações, nas quais são inteiramente de sua responsabilidade. A forma-sujeito virtual se apropria das formações discursivas elaboradas no capitalismo e na modernidade.

Ao construir o discurso do sujeito consumidor, ou mesmo do indivíduo livre e com consciência, o capitalismo e/ou a modernidade contribuíram para que a forma-sujeito virtual conseguisse estabelecer uma forma discursiva entre os indivíduos das mídias sociais. Esses indivíduos ao participarem dos sites de relacionamento e dos portais e deixarem seus comentários estão inseridos na lógica do consumo, agora o virtual e também a do indivíduo que possui os deveres e os direitos de enunciar.

Porto (2010) ressalta os sujeitos ao se expressarem passam ser mediações do discurso, e a própria enunciação percebe-se as posições que os indivíduos ocupam nos espaços em que os sujeitos se localizam. A leitura enunciativa, proposta como instrumento de análise pelo autor, torna-se então uma estratégia de análise para a compreensão de como os sujeitos enunciam: 
Esta quarta leitura, a enunciativa, mostra como os enunciados se formam, em que contexto de enunciação e de que maneira os sujeitos operam a passagem de suas idéias às suas frases e discursos. A enunciação é uma ferramenta lingüística e social que se parece com a caixa de marchas de um carro; através de ato de embreagem buscam-se as marchas de que o carro precisa se locomover. (PORTO, 2010, p. 38).

A metáfora da enunciação como caixa de marchas de um carro, evidencia como os internautas se utilizam de tipos de enunciações para expressarem suas opiniões. Os sites de relacionamento e os portais como o Yahoo! e Folha. Uol tornam-se espaços para que indivíduos, ocupem posições de sujeitos virtuais. Esses sujeitos participando de comunidades virtuais, blogs ou microblogs e também dos portais de notícias, se tornam enunciadores, estabelecendo sentidos, mas também assujeitados de formações discursivas.

A “mobilização" que as mídias sociais oferecem aos indivíduos, somente é possível pela capacidade da internet,em propiciar ferramentas para que os sujeitos virtuais possam emitir seus comentários. Ferramentas como salas de bate papo, comunidades virtuais e espaço para comentários em blogs ou microblogs possibilitaram que usuários pudessem emitir seus comentários sobre a temática da homossexualidade, exibida pela telenovela Insensato Coração. A internet nos últimos anos tornou-se um lugar em que indivíduos procuram externalizar suas subjetividades, isto é, participando dos discursos sobre subjetividade. O sujeito virtual talvez seja um tipo de sujeito que está sendo construído historicamente nessas últimas décadas. Como observou Orlandi (2009) cada momento histórico condiciona o tipo de sujeito. Orlandi, a partir de C. Haroche (1987) exemplifica que no passado ocorreram "formas-sujeito".

Pierre Lévy em Cibercultura (1999) analisa como o processo virtual estabelece novas configurações e experiências sociais. Para o filósofo a internet estabeleceu um ciberespaço que possibilita que os indivíduos possam utilizar esse espaço para que os indivíduos possam não apenas se comunicarem, mas expandirem a própria comunicação:

Eu defino o ciberespaço como o espaço de comunicação aberto pela interconexão mundial dos computadores e da memória dos computadores. Essa definição inclui o conjunto dos sistemas de comunicação eletrônicos (aí incluídos os conjuntos de rede hertzianas e telefônicas clássicas), na medida em que transmitem informações provenientes 
de fontes digitais ou destinadas á digitalização. (...) A perspectiva da digitalização geral das informações provavelmente tornará o ciberespaço o principal cana de comunicação e suporte de memória da humanidade a partir do início do próximo século. (LÉVY, 1999, p. 93-94).

Se continuarmos na perspectiva de Lévy percebe-se que esse ciberespaço se ampliou, principalmente com o advento e o impacto das mídias sociais. MiIhões de pessoas no mundo inteiro se conectam diariamente, para postar comentários, estabelecer diálogos em comunidades virtuais e bate papos através de ferramentais disponíveis como o Messenger da Microsoft, do Yahoo! e do Google . Vale lembrar, que essa análise se ocupa apenas da dimensão formal desse processo, sem se ater no conteúdo dos comentários.

Para compreender, portanto, esse processo na atualidade é importante compreender como os indivíduos agem e realizam experiências na contemporaneidade, que ainda é considerada como moderna, ou para outros com pósmoderna. Autores como Z. Bauman considera que os indivíduos vivenciam na atualidade a chamada modernidade líquida. Na modernidade "tradicional", com o rompimento com a pré-modernidade, os indivíduos eram estimulados a desenvolver autoconsciência para a emancipação e as escolhas individualizadas. Na modernidade líquida os indivíduos escolhem de forma fluída, contrariando as características do modelo cidadão/iluminista.

Os indivíduos na modernidade líquida são submetidos numa incessante escoIha propiciada pelo intenso desenvolvimento tecnológico e capitalista. Os indivíduos não optam, apenas escolhem. Eles são condicionados a escolherem numa infinidade de produtos, situações e pessoas. Os sites de relacionamento e as ferramentas de mensagens instantâneas são espaços em que indivíduos desenvolvem essa liberdade condicionada? Para refletir a questão recorremos à Bauman:

As novas tecnologias não são mera resposta a uma necessidade: de modo algum sua aparição foi determinada pela demanda popular. Trata-se antes de demanda determinada pela disponibilidade da nova tecnologia. Tenha a necessidade existido ou não, a demanda por novos produtos é posterior a sua introdução. Nesse sentido, a suposição de que a demanda cria a oferta é invertida pelos fornecedores, que estimulam ativamente a demanda por meio de suas estratégias de marketing. (BAUMAN, 2010, 240) 
Essa percepção de Bauman remete para a análise de que os indivíduos ao utilizarem as ferramentas tecnológicas, os fazem não apenas por escolhas, mas motivações inerentes às relações da sociedade contemporânea. Motivações como a forma-discurso que destacamos, a partir da análise de Orlandi (2009) e que condiciona os indivíduos nessa modernidade líquida a se tornarem sujeitos "virtuais". O capitalismo com suas estruturas de consumo e publicidade estimulam os indivíduos a "escolherem" de acordo com suas estratégias, e por isso, os sites de relacionamento são espaços promissores de publicidade.

A forma sujeito virtual está cada vez mais condicionada às necessidades, interesses e as demandas do capitalismo e da revolução tecnológica. Existe um discurso que estimula os indivíduos a adquirirem os lançamentos ininterruptos de gadgets tecnológicos, e a participação dos mesmos nos sites de relacionamento. As quantidades de indivíduos que mantém perfis nesses sites mostram esse estímulo. Por exemplo, o Facebook, possui atualmente mais de 700 milhões de usuários, tornando-se o segundo site mais visitado do mundo. No Brasil tornou-se o site de relacionamento mais acessado, superando seu "concorrente" direto o Orkut. Segundo dados atuais o Facebook possui 36 milhões de usuários, enquanto o Orkut, 34 milhões. O Brasil tornou-se o quarto país com maio número de usuários do Facebook e o segundo do Orkut. A diferença pode parecer pequena, mas se analisarmos a expansão do Facebook nos anos de 2010-2011 (194\%) ressaltará um crescimento exponencial.

Uma percepção relevante no perfil dos usuários dos sites de relacionamento e o desdobramento do conteúdo e serve como ilustração, é que nos principais sites de relacionamento existentes no Brasil (Facebook e Orkut) muitos dos comentários que os indivíduos realizam, nos seus perfis, nas comunidades virtuais e nos espaços dos portais destinados as opiniões dos internautas percebemos que são destinados à comentários sobre produtos da televisão, especialmente da telenovela. Um exemplo importante é o espaço em que usuários das mídias sociais comentam programas televisivos como os reality shows, principalmente do Big Brother Brasil.

Esses usuários podem ser considerados não apenas indivíduos "assujeitados" à forma sujeito virtual, mas também são consumidores de produtos culturais e/ou midiáticos. Porém, esse consumo é realizado de forma complexa e contraditória e não apenas podemos pensar o consumo de forma unívoca e 
tangível. Para Bauman, a sociedades atuais se afastaram da modernidade, ou do projeto moderno associado à civilização ocidental. Motivado principalmente pela globalização que rompeu fronteiras econômicas e culturais, produzindo novas experiências para os indivíduos.

\section{CONCLUSÃO}

Identificar os usuários das mídias sociais, como consumidores dos produtos digitais e também de informações remete para a questão da forma sujeito virtual. Os indivíduos na atualidade estão condicionados pela forma sujeito virtual, diferentemente das apontadas - através das análises de Haroche (19992 anteriormente como a forma sujeito religiosa e política. Esse condicionamento pode ser percebido no alcance em que as mídias sociais possuem na atualidade e a participação dos indivíduos nessas plataformas virtuais. Para compreender esse processo recorreremos as análises propostas pro P. Lévy.

Se a forma sujeito religiosa, como apontou Haroche (1992), é atravessada pelo discurso religioso, a forma sujeito jurídica é atravessada pelo discurso do direito então a forma sujeito virtual é atravessada pelo discurso da digitalização das relações sociais e dos produtos que propiciam essa digitalização. A forma sujeito virtual se caracteriza não por uma linguagem que procura a autonomia do indivíduo, como desejava o iluminismo e que atravessou a forma sujeito jurídica. Tampouco, a salvação e o ascetismo como buscava a forma sujeito religiosa. O que a forma sujeito virtual procura é a inserção dos indivíduos no discurso de digitalização da vida social.

A forma sujeito virtual não elimina outras formas sujeitos que ainda existem, mesmo a jurídica. Mesmo que possamos identificar outras formas sujeito, que são muitas, a forma sujeito virtual na contemporaneidade está assumindo uma posição quase determinista. As análises propostas pelos autores destacados (LÉVY 1999; CASTELLS, 1999; BAUMAN, 2001) nos remetem para muitas questões, nas quais algumas exploramos neste texto. Uma questão pertinente e que consideramos central é como os indivíduos ao tornarem-se integrantes do universo virtual, ou mesmo da network society, ocorre o processo de construção da linguagem utilizada pelos usuários. 


\section{REFERÊNCIAS}

ALTHUSSER, Louis. Freud e Lacan. Marx e Freud: introdução crítica histórica. 2 ed. Rio de Janeiro: Edições Graal, 1985.

AUTHIER-REVEUZ, Jacqueline. Palavras incertas: as não-coincidências do dizer. Campinas: Editora da UNICAMP, 1998.

BAUMAN, Zygmunt. Modernidade líquida. Rio de Janeiro: Jorge Zahar, 2001.

CASTELLS, Manuel. A sociedade em rede. 2 ed. São Paulo: Paz e Terra, 1991

FOUCAULT, Michel. Microfísica do Poder. 15 ed. Rio de Janeiro: Edições Graal, 2000.

. A Ordem do discurso. 14 ed. São Paulo: Edições Loyola, 2006.

HAROCHE, Claudine. Fazer dizer, querer dizer. São Paulo: Editora Hucitec, 1992.

LÉVY, Pierre. Cibercultura. São Paulo. Ed 34, 1999.

ORLANDI, Eni Puccinelli. Análise do discurso: princípios e procedimentos. 8 ed. Campinas: Pontes, 2008. tes, 2006.

. A linguagem e seu funcionamento: as formas do discurso. 4 ed. Campinhas: Pon-

. Discurso e texto: formação e circulação dos sentidos. Campinas: Pontes, 2001.

PÊCHEUX, Michel. O discurso: estrutura ou acontecimento. 5 ed. Campinas: Pontes Editores, 2008.

. Análise do discurso. 2 ed. Campinhas: Pontes, 2001.

. Semântica e discurso: uma crítica à afirmação do óbvio. 4 ed. Campinhas: Editora da UNICAMP, 2004.

PORTO, Sérgio Dayrell. Análise do discurso: o caminho das seis leituras interpretativas em massa folhada. Brasília: Casa das Musas, 2010.

. Sexo, afeta e era tecnológica: um estudo de chats na internet. Brasília: Editora da Universidade de Brasília, 1999.

SODRÉ, Muniz. Redes sociais ainda não mudaram a ação política. 23/08/2011. In http:// www.unb.br/noticias/unbagencia/unbagencia.php?id=5538. Acessado em 15/07/2012.

RECEBIDO EM: 30/06/2013

ACEITO PARA PUBLICAÇÃO: 28/07/2013 


\section{Plábio Marcos Martins Desidério}

Graduação em Filosofia, Mestre em Sociologia e Doutor em Comunicação. Professor do Colegiado de História: UFT - Campus Araguaína (TO). Professor do Programa de Pós-Graduação em Letras: Mestrado em Rede - ProfLetras: UFT - Campus - Araguaína (TO). Estuda narrativas audiovisuais, recepção na web e cinema. 
